\title{
IMPUNIDADE DAS INFRAÇÕES A REGRAS DE AVIAÇÃO COMETIDAS EM ALTO MAR
}

\author{
(A propósito do art. 12 da Convenção de Chicago). \\ OCTANNY SILVEIRA DA MOTA $(*)$
}

A aeronáutica revelou-se, durante o último grande conflito, forma de transporte para a qual não havia pontos remotos nem distâncias invencíveis. E estando, como se fazia evidente, destinada a operar em escala mundial no após guerra, a aviação requeria, de maneira clara, disciplina da mesma escala. Nessa visível exigência encontrou justificativa o convite dirigido pelos Estados Unidos da América, em agosto de 1944, a várias nações, no sentido de que participassem de uma conferência, onde se discutiria o assunto, com vistas à celebração de acôrdo internacional. Veio tal conferência a realizar-se em novembro-dezembro do mesmo ano e dela nasceu a Convenção da Aviação Civil Internacional, conhecida como Convenção de Chicago e ora em vigor.

Concorda-se geralmente com que os resultados mais notáveis obtidos nessa reunião disseram respeito ao campo técnico e tem-se repetido a opinião segundo a qual "if the Conference had accomplished nothing else, this work would have justified the time and effort expended" (1) - opinião, contudo, que não nos deve levar a diminuir o significado de anteriores realizações, nas quais, aliás, os trabalhos de Chicago se apoiaram largamente.

Preocupação central da Conferência girou, todavia e em verdade, em torno do propósito de garantir segurança é facilidade ao vôo, por meio do estabelecimento de padrões técnicos que, adotados pelos diversos países, se fizessem vigorantes uniformemente em âmbito internacional (2).

(*) "Master of Laws" (LL.M.), Universidade de Miami; Professor Assistente de Direito, Instituto Tecnológico de Aeronáutica.

(1) Jacob Schenkman - "International Civil Aviation Organization" pag. 100 (Genebra, 1955).

(2) John C. Cooper - "Air Transport and World Organization", in Yale Law Journal, vol. 55 (1945-46), pag. 1191. 
Contêm-se tais padrões nos chamados Anexos à Convenção de Chicago e sua elaboração incumbe, agora, a um organismo permanente, brotado da Conferência e denominado Organização da Aviação Civil Interncional (indicada, geralmente, pela sigla inglesa I.C.A.O.) (3).

O caráter dêsses Anexos tem sido objeto de crítica, especialmente por parte de internacionalistas, por estarem privados da força impositiva de que dispunham os Anexos à Convenção de Paris, de 1919 (4). Com efeito, devem os Anexos à Convenção de Chicago ser postos em vigor nos diferentes Estados através dos meios prescritos pelas diferentes legislações, sendo esse fato muitas vêzes enxergado, como passo atrás no desejável processo de internacionalização da aeronáutica. Sem pretender contestar essas críticas, assinalaremos que elas devem ser pesadas contra os largos poderes concedidos ao Conselho da I.C.A.O. - certamente mais amplos que os atribuidos à extinta C.I.N.A. - no que se refere ao estabelecimento de regras de vôo e manobra de aeronaves sôbre o alto mar

Importa, por outro lado, não esquecer que, embora autorizados, por ocasião do processo de adoção dos Anexos, a manifestar divergências (5) quanto aos padrões nestes contido, os Estados têm rara. mente usado dessa faculdade. A propósito informava SCHENKMAN, em 1955: "... the maximum number of disaprovals notified in relation to any one international standard is eight" (6). MANKIEWICZ, em 1958, corroborava essa afirmação, estendendo-a até a data em que escrevia (7) e, no particular, a situação não parece ter-se alterado. O fato diz claro, a um tempo, da excelência do trabalho que vem executando a I.C.A.O., e de apôio que the vem sendo emprestado pelas nações filiadas. A uma e outras compete importante papel e, se a iniciativa cabe à I.C.A.O., o processo de internacionalização só se pode completar com a contribuição individual dos Estados-membros, nos têrmos acima indicados.

Essa contribuição não tem faltado e os Estados têm feito mais do que simplesmente acolher os Anexos como disciplinadores do transporte aéreo internacional regular: têm-nos transformado em preceitos de observância obrigatória em relação ao transporte aéreo internacional não regular, bem como em relação aos vôos que se desenvolvem no interior de fronteiras nacionais. $E$, assim, a uniformidade das regras veículadas pelos Anexos vem assumindo, realmente, feição mundial, o que decorre do fato de serem tais regras,

(3) Convenção de Chicago, Parte 11, art. 43 e seguintes.

(4) Ver Paulo Ernesto Tolle - "Sobre os Anexos à Convenção de Chicago", in Revista dos Tribunais, vol. 295, pag. 755 (São Paulo, 1960).

(5) Convenção de Chicago, art. 38.

(6) Jacob Schenkman, o.c., pag. 263.

(7) R.N. Markiewicz - "Aspects et problèmes du droit pénal de l'aviation internationale", in Annuaire Français de Droit International, vol. IV (1958), pag. 114. 
em verdade, obra de um legislador único, embora postas em vigor por Estados diversos, em promulgações multiplicadas.

Da semelhança de tais regras deflui, como consequência natural, a semelhança dos preceitos que visam resguardá-las, ou seja, dos dispositivos que, por necessidade jurídica, são promulgados para estabelecer as sanções aplicáveis a eventuais infratores. No consagrar essas disposições repressivas, observam as diferentes legislações critérios vários; sem a preocupação de examiná-los, anotaremos que, neste setor - dadas as características técnicas sempre cambiantes da aviação a flexibilidade dos preceitos penais se faz ideal, pois, de outra maneira, a lei estará sujeita a constantemente enfermar de anacronismo e constantemente a reclamar reformas.

Neste sentido, modelo pode ser encontrado na Lei Federal de Navegação Aérea, da Suiça, promulgada em dezembro de 1948. O artigo 91 dessa lei prevê aplicação da pena de prisão de, no máximo, três meses ou de multa de, no mínimo, dois mil francos, no caso de infração dos preceitos da mesma lei, de seus regulamentos e de quaisquer outras disposições baixadas em função dela ou de infração de ordenamentos oriundos de acôrdos internacionais relativos à navegação aérea (8). Esse texto legal merece de LACOUR comentário que nos parece de subscrever: "Ce moyen uniforme et général de sanction a pour but de supprimer l'énumeration dans la loi et la répetition dans chaque règlement ou ordonnance des prescriptions pénales. Le risque de se trouver en presence de "leges imperfectal" est ainsi évité, sans entrainer pour autant une fastidieuse énumeration dans chacun des textos légaux (9).

Na América Latina, entretanto, se, no interior das fronteiras do Estado, o legislador preocupou-se com assegurar a observância das regras de vôo e manobra de aeronaves o mesmo não fêz, ao que nos consta, no sentido de que essas mesmas regras sejam observadas por aeronaves de matrícula nacional para além dos limites territoriais. Surge, consequentemente situação paradoxal em que regras internacionais de navegação aérea - estabelecidas pelos Anexos são sancionadas quando reduzidas a dimensão nacional, mas sua inobservância nenhuma punição entranha enquanto como regras internacionais permanecem.

Sob este prisma, o muitas vezes chamado Direito Penal Aero-

(8) $E^{\prime}$ o seguinte o texto do art. 91 da lei suiça, em tradução inglesa incluida na coletânea intitulada "Air Laws and Treaties of the Worlad, an annotated compilation prepared for the Committee on Science and Astronautics; U.S. House of Representatives (1961): "Art. 91. Misdemeanors. Any person who violates this law, the regulations issued in application thereof, or the provision of an agreement concerning air navigation, particularly the rules concerning air traffic, air police, ground installations, aircraft, or air personnel shall be punished by arrest up to three months or a fine up to two thousand francs".

(9) J. T. Lacour - "Le dreit pénal aérien stisse", in Revue Française de Droit Aérien, vol. 6, pag. 267 (1952). 
náutico, tal como o praticam os diferentes Estados nos respectivos territórios, revela avanço sobre o Direito Penal Aeronáutico Internacional. Colocá-los lado a lado, concedendo ao último a eficácia do primeiro, é tarefa dos legisladores nacionais, que têm permanecido inertes em campo onde a lei internacional já desempenhou seu papel.

Interessando-nos o estudo de infrações penais relacionadas com a navegação aérea, na América Latin, daremos prticular atenção a êste assunto. Parece-nos, com efeito, que, se os países latino-americanos se empenhassem em completar a obra de internacionalização já iniciada, promulgando atos legislativos de acôrdo com o que sugere e requer a Convenção de Chicago, amplo setor ficaria coberto.

Aprofundemos a questão, que emerge do artigo 12 da Convenção de Chicago, em cuja análise, por isso mesmo, nos deteremos.

\section{II}

Dentre os projetos de acôrdo internacional sôbre navegação aérea que a Conferência de Chicago encontrou diante de si, apenas um, o apresentado pelo Canadá, continha disposição semelhante à que hoje constitui o artigo 12 da Convenção. Lia-se no art. XXXII do projeto canadense:

"Each member Stato undertakes to adopt measures to assure that every aircraft flying above the limits of its territory and that every aircraft, wherever it may be, carrying its nationality mark, shall comply with the regulations contained in Annex...

Each of the member States undertakes to ensure the prosecution and punishment of all persons contravening these regulations" (10).

Êsse dispositivo prendia-se nìtidamente ao que preceituava a Convenção Relativa à Regulamentação da Navegação Aérea, assinada em Paris, aos 13 de outubro de 1919 (11), cujo art. 25 rezava:

"Chacun des. Etats contractants s'engage à prende les mesures propres à assurer que teus aéronefs naviguant au dessus de son territoire, ainsi que tous aéronefs portant $1 .^{a}$ marque de sa nationalité et en quelque lieu qu'ils se trouvent se conformeront aux règlements prévus à I'Annex D.

Chacun des Etats contractants s'engage à assurer 1.a poursuite et les punitions des contrevenants".

(10) "Proceedings of the Internacional Civil Aviation Conference". U. S. Department of State. Publication n.o 2820, vol. 1, pag. 585 (1948).

(11) Texto em "International Legislation", editada por Hudson, vol. 1, pag. 359 (1931). 
O artigo da proposta canadense não foi, de início, objeto de estudo por parte de qualquer das comissões e subcomissões criadas pela Conferência, (12) foi considerado, entretanto, quando os trabalhos da reunião iam mais avançados e já se admitira ser impossível completar a redação dos Anexos ao mesmo tempo que a da Convenção e ser necessário encontrar, para adoção e reforma dos mesmos Anexos, fórmula suficientemente flexível para que não se chocasse contra dispositivos constitucionais estatais. A Comissão de Redação, tendo em conta os fatos acima, preparou documento em que o art. XXXII da proposta canadense reapareceu, sob número 11 $A$, vasada nos seguintes têrmos:

Rules of the air, etc.

Each contracting State undertakes to adopt measures to assure that every aircraft flying over or maneuvering within its territory and that every aircraft carrying its nationality mark, wherever it may be, shall comply with the rules and regulations relating te the flight and maneuver of aircraft there in force, and to keep its own regulations uniform, to the greatest possible extent, with those esfablished from time to time under this Convention. Over the high seas, the rules in force shall be those established under this Convention.

Each contracting State undertakes to ensure the procecution of all persons violating the regulations applicable (13).

Com ligeiras modificações de forma, porém sem qualquer alteração de fundo, esse art. 11 A veio a constituir-se, finalmente, no art. 12 da Convenção de Chicago, sendo o seguinte seu texto original autêntico:

Each contracting State undertakes to adopt measures to insure that every aircraft flying over or maneuvering within its territory and that every aircraft carryings its nationality mark, wherever such aircráft may be, shall comply with the rules and regulations relating to the flight and maneouver of aircraft there in force. Each contracting State undertakes to keep its own regulations in these respects uniform, to the greatest possible extent, with those established from time to time under this Convention. Over the high seas, the rules in force shall be those established under this Convention.

Each contracting State undertakes to insure the prosection of all persons violating the regulations applicable (14).

(12) "Preceedings" cit., vol. 1, pags. 648, 677, 679 e 698.

(13) Idem; ibidem, pag. 668

(14) Esse texto foi redigido ùnicamente em inglês. O fecho da Convenção de Chicago refere-se a versões autênticas a serem redigidas em espanhol e francês, porém tais versőes 
Estabelecidos êsses pontos, tentemos assinalar e compreender 0 sentido das transformações operadas ao longo do caminho que levou do art. XXXII da proposta canadense ao art. 12, tal como a Convenção o consagra.

Anotemos, antes de tudo, as modificações maiores que se introduziram: dizem elas respeito às regras a serem observadas durante o sobrevôo do alto mar e ao duplo compromisso assumido pelos Estados contratantes, quanto a manterem o maior grau possível de uniformidade entre as regras por êles prescritas e as estabelecidas de acôrdo com a Convenção e quanto a compelirem as aeronaves nacionais à observância das regras de vôo e manobra em vigor "onde quer que se encontrem".

Essas transformações refletiram, de maneira imediata, a orientação que se firmava com o avanço dos trabalhos da Conferência. Tornado claro que os Anexos não poderiam ser postos em vigor ao mesmo tempo que a Convenção (15), assentada a forma por que êles se. riam feitos de observância obrigatória nos territórios dos diferentes Estados e concordado quanto à possibilidade de afastamento entre padrões nacionais e internacionais, a proposta canadense - concebida em têrmos da Convenção de Paris - cedeu passo, naturalmente, a novo texto. Vem ao caso, entretanto, apontar a conexão, especialmente para assinalar o objetivo de uniformidade internacional, presente em ambos os dispositivos e simplesmente perseguido em cada qual dêles por processos que apenas diferem na medida em que devem adaptar-se a linhas mestras diferentes.

Para construir a interpretação do art. 12 e salientar os compromissos à vista dele assumidos pelos Estados - membros, importa, dentro da sistemática da Convenção, aproximá-los das disposições a que mais se relaciona.

Cabe ao Conselho da I.C.A.O., em têrmos de obrigatoriedade, de acôrdo com o art. 54 (1) da Convenção (16), aḍotar normas e práticas recomendadas (17), informando de tal adoção os Estados-mem-

nunca foram preparadas. Em 1947, o governo dos Estados Unidos da América propôs que - assunto fosse considerado pela I.C.A.O. A Assembléia dessa Organização resolveu, em junho de 1949 (Resolução A 3-2., constante do Dec. da 1.C.A.O., n.0 7670, pag. 107) incumbir o Conselho do preparo de textos em espanhol e francês "it being unders. tood that these texts will be used only for internal purposes of the Organization". Por esse motivo, citaremos sempre o texto inglês da Convenção. Texto nas três línguas fi. gura no Doc. da I.C.A.O., n.0 7300/2.

(15) A Convenção foi assinada em dezembro de 1944 e o primeiro grupo de Anexos adotado em 1948. Veja-se o artigo de E. Pépin intitulado "I.C.A.O., and other agencies dasling with air navigation" in Journal of Air Law and Commerce, vol. 19, pag. 152 (1952).

(16) Art. 54 - The Council shall: ............

(1) Adopt... international standards and recomended practices; for convenience, designate them as Anexes to this Convention.; and notify all contracting States of the action taken.

(17) Na primeira reunião da Assembléia da 1.C.A.O. (Monteral, $6-27$ de maio de 1947) normas e práticas recomendadas foram assim definidas: "... Standard means any specification for physical characteristics, configuration, material, performance, personnel, or procedure, the 
bros; nesse mesmo artigo, aliás, é que se diz que tais normas e práticas serão, por conveniência, chamadas Anexos. As disposições do art. 54 completam-se pelas do art. 90 (18), concernentes ao processo de adoção e emenda dos Anexos. Importa lembrar também o art. 38 (19) que autoriza os Estados a manifestarem divergências relativamente aos padrões internacionais propostos, caso em que ficam obrigados a notificar imediatamente a I.C.A.O.

O propósito de uniformidade objetivado pela Convenção no que se refere à navegação aérea é realçado pelo primeiro parágrafo do art. 37 (20) e, neste sentido, o art. 12 constitui apenas um dos dispositivos por via dos quais se procura estabelecer e resguardar essa uniformidade em certo campo, ou seja, no campo das regras do ar.

O Canadá propusera que a uniformidade surgisse como decorrência imediata da Convenção, da qual os Anexos, em apenso, fariam parte integrante (21). Tomando orientação diversa, a Conferência de

uniform application of which is recognized as necessary for the safety or regularity of international air navigation and to which Member States will conform in accordance with the Convention; in the event of impossibility of compliance, notification to the Council is compulsory under Article 38 of the Convention...".

"... Recommended Pratice means any specification for physical characterístics, configuration, material, performance, personnel, or procedure, the uniform application of which is recognized as desirable in the interest of safety, regularity or efficiency of international air navigation, and tho which Member States will endeavour to conform in accordance with the Convention...".

(18) Art. 90 - Adoption and Ammendment of Annexes:

(a) The Adoption by the Council of the Annexes described in Article 54, subparagraph (1), shall require the vote of two-thirds of the Council at a maeting called for that purpose and shall then be submitted by the Council to each contracting State. Any such Annex or any amemdment of an Annex shall become effective within three months after its submission to the contracting States or at the end of such longer period of time as the Council may precribe, unless in the meantime a majority of the contracting States register their desapproval with the Council.

(b) The Council shall immediately notify all contracting States of the coming into forcs of any Annex or amendment thereto.

(19) Art. 38 - Any State which finds it impracticable to comply in all respects with any such international standard or procedure, or to brings its own regulations or practices into full accord with any intenational standard or procedure after amendment of the latter, or which deems it necessary to adopt regulations or pratices differing in any particular respect from those established by an international standard, shall give immediate notification to the International Civil Aviation Organization of the diferences between its own practice and that established by the international standard. In the case of amendments to in. ternational standards, any State which does not make the appropriate amendments to its own regulations or practices shall give notice to the Council within sixty days of the amendment to the international standard, or indicate the action which it proposes to take. In any such case, the Council shall make immediate notification to all other States of the difference wich exists between one or more features of an international standard and the corresponding national practice of that State.

(20) Art. 37 - Each contracting State undertakes to collaborate in securing the highest practicable degree of uniformity in regulations, standards, precedures, and organization in re. lation to aircraft, personnel, airways and auxiliary services in all matters in which such uniformity will facilitate and improve air navigation.

(21) A proposta canadense inclula art. XLV, assim redigido: "The provisions of the present Convention are completed by the Annexes... which shall have the same effect and shall co. me into force at the same time as the Convention itself". 
Chicago, nem por isso, deixou de perseguir o mesmo objetivo e, para colimá-lo no setor das regras de circulação aérea, elaborou o art. 12.

\section{$|1|$}

Buscando aprofundar o sentido dêsse dispositivo, parece-nos conveniente isolar e examinar, de início, sua terceira sentença: "Over the high seas, the rules in force shall be these established under this Convention".

Do texto ressalta, de pronto, contraste entre seu caráter compulsório e o caráter de não obrigatoriedade que marca os demais preceitos contidos no mesmo artigo e é próprio, normalmente, da legislação técnica adotada pela Convenção. Relativamente a seus respectivos territórios, podem os Estados manifestar divergências quanto às normas e práticas recomendadas a êles submetidas pela I.C.A.O., no que se refere ao alto mar, entretanto, divergências não são admitidas $e$, consequentemente, razão não há para que o Conselho da I.C.A.O., submeta à apreciação dos Estados-membros as regras de navegação aérea a serem ali observadas. $O$ Conselho simblesmente as comunica aos membros Estados. Dara cumbrimento. Sob êste prisma, é amplo - superior ao de que gozou a C.I.N.A. o poder legislativo concedido ao Conselho da I.C.A.O. (22). Composto de representantes de vinte e um Estado (23) e necessitando o Conselho do voto de dois terços de seus membros para estabelecer ou modificar Anexos, (24) equivale isso a dizer que catorze Estados podem impor a todos os demais a obrigação compulsória de obedecer, sem afastamente possível, a certas e determinadas regras relativas a vôo e manobra de aeronaves sôbre o alto mar.

Dada a existência dêsse poder amplo, importa indagar o âmbito a que seu exercício se estende. Na sentença que estamos examinando, há apenas referência a "rules in force". Mas não há dúvida de que tal expressão prende-se à sentença inicial do mesmo art. 12, onde se alude a "rules and regulations relating to the flight and maneuver of aircraft". . Conclua-se, pois, que o poder do Conselho se restringe ao direito de impor observância de regras de vôo e manobra de aeronaves sôbre o alto mar.

O caráter impositivo de preceito, embora apareça estranho no corpo da Convenção, é, não obstante, de todo justificado.

'É necessário, no interêsse de segurança da navegação aérea. que, numa área determinada, imperem regras de vôo e manobra uniformes. Pôde a Convenção conceder que os Estados, com referência

(22) Ver H. Drion - "The Council of I.C.A.O., as international legislator over the high seas", in "Studi in onore di A. Ambresini, pag. '23 (Milão, 1957).

(23) Convenção de Chicago, art. 50.

(11) Convenção de Chicago, art. 90. 
a seus próprios territórios, manifestassem divergências em relação aos padrões internacionais porque essas divergências, uma vez expressas e comunicadas aos demais Estados-membros, passam a revestir-se de caráter de unicidade. Os padrões internacionais, tal como alterados pelas divergências proclamadas por um Estado, são as regras únicas vigorantes no interior das fronteiras dêsse Estado - e, assim, a uniformidade não é prejudicada. No que toca ao alto mar, entretanto, impunha-se proceder de maneira diversa para atingir o mesmo objetivo. Nada era possível deixar à discreção dos Estados, pois não exercendo qualquer dêles soberania sôbre o alto mar ou sôbre o espaço aéreo superjacente, nenhum dêles estaria em condições de ditar regras aos demais; não se poderia admitir, de outra parte, que cada qual dos Estados estipulasse regras próprias a serem observadas por aeronaves nacionaís quando em vôo sôbre o alto mar, pois sempre estaria presente a desastrosa possibilidade de conflitos. A solução natural era entregar o poder de formular regras de vôo e manobra de aeronaves, sôbre o alto mar, a um organismo internacional. Por tal solução optou a Conferência de Chicago, traduzindo-a na curta frase de largo alcance que constitui a terceira sentença do art. 12 da Convenção.

A vista dos têrmos em que tal frase é redigida, caberia indagar se estão os Estados impedidos, de forma absoluta de estabelecer regras de qualquer espécie concernentes a vôo e manobra de aeronaves sobre o alto mar. A resposta a tal indagação parece-nos que deva ser negativa, mas condicional. Os Estados não estão impedidos de impor preceitos de observância obrigatória por parte de aeronaves que voem ou manobrem sôbre o alto mar. Mas só podem impô-los sob a dupla condição de que tais preceitos obriguem apenas aeronaves nacionais e de que não se choquem contra os estabelecidos pelo Conselho da I.C.A.O. A primeira condição decorre do fato de que Estado algum detém soberania sôbre o alto mar e deflui a segunda do princípio que impõe honrar o pacto celebrado.

Outra indagação sugerida pelo assunto de que nos vimos ocupando diz respeito à responsabilidade pela imposição de castigo a eventuais infratores. A quem caberá puní-los? $O$ poder legislativo da I.C.A.O., não envolve qualquer poder punitivo e, à vista disso, tem-se respondido que a aplicação de sanções incumbe ao Estado de matrícula da aeronave. Justifica-se tal posição afirmando que a aeronave, quando sobrevoa o alto mar - cruzando espaço aéreo que a nenhuma soberania se sujeita - está presa ao Estado de sujas insígnias é portadora e, dessa forma, só a êste compete reprimir violações. Essse entendimento pode ser reforçado pela circunstância de que, no mesmo art. 12, os Estados se comprometem a assegurar que aeronaves de matrícula nacional cumpram com as regras de vôo e manobra vigorantes "onde quer que tais aeronaves se encontrem". Nes te ponto, entretanto, não parece seja essa a solução única. DRION 
alude a uma alternativa possível quando projeta 0 assunto para $\circ$ campo do Direito Internacional e, mencionando o "caso Lotus", opina que não apenas o Estado de matrícula da aeronave infratora, mas ainda, por exemplo, o Estado de matrícula da aeronave prejudicada pela infração cometida são competentes para a aplicação de sanções (25).

Terminando estas considerações relativas ao vôo e manobra de aeronaves sôbre o alto mar, cabe lembrar que essa expressão - alto mar - não tem sentido preciso. Na mais recente ocasião em que se discutiu o assunto em plano internacional - Genebra, 1958 - definiu se o alto mar de forma negativa, estabelecendo que êle corresponde a tôdas as porções de mar não incluidas nas águas territoriais ou nas águas interiores de um Estado (26). Desde que não se chegou a acôrdo quanto à extensão das águas territoriais, pois diferentes países mantiveram posições inconciliáveis, os limites do alto mar ficaram, por consequência, também indefinidos.

\section{i $\mathrm{V}$}

Conquanto o art. 12 se refira apenas a alto mar, parece-nos junto entender que o regime aplicável ao sobrevôo dêste se estenda vàlidamente a todos os outros pontos do planeta não sujeitos a efetivo poder soberano, pois esta ausência de soberania é, em verdade, a razão que explica o sistema especial vigorante sôbre o alto mar.

Passando ao exame das demais disposições que constituem o art. 12 da Convenção de Chicago, assinalemos que elas têm objetivo semelhante ao presente na sentença já examinada: assegurar uniformidades das regras de vôo e manobra de aeronaves, em regiões ou tras que não o espaço aéreo sôbre o alto mar. O segundo período do artigo em causa sublinha, com efeito, o compromisso de os Estados manterem seus regulamentos, no que tange a vôq e manobra de aeronaves, conformes, "na maior extensão possível", aos que venham a constar dos Anexos. E isso não sem antes exigir dos mesmos Estados a consagração de medidas capazes de assegurar o cumprimento dessas mesmas regras, seịa nos territórios respectivos - relativamente a quaisquer aeronaves - seja em qualquer ponto em que se encontrem - relativamente às aeronaves nacionais. E vai adiante o art. 12 - em sua sentença final - com o requerer dos Estados o compromisso de perseguição das eventuais infrações.

Se, por força do art. 12, cada qual dos membros da Convenção de Chicago obriga-se, de um lado, a proceder contra quaisquer aeronaves que, nos limites de seu território, deixem de observar regras relativas a vôo e manobra e, de outra parte, compromete-se a proce-

(25) H. Drion, c.c.

(26) Convenção Relativa ao Alto Mar, assinada em Genebra, aos 29 de abril de 1958, art. 1. 
der contra aeronaves de matrícula nacional que violem regras dessa mesma natureza, "wherever such aircraft may be", impõe-se conclusão que realça traço característico do Direito Penal Aeronáutico: repressão, em têrmos de lei nacional, de infrações cujos elementos constitutivos são definidos por lei estrangeira. Efetivamente, ao punir aeronave nacional que, para além dos limites territoriais, haja violado regulamentos de vôo ou manobra, o Estado estará sancionando preceitos estrangeiros, preceitos "there in force". E que êsses regulamen. tos - dada a uniformidade internacional já lembrada - sejam muito provávelmente semelhantes aos do Estado sancionador é irrelevante, pois - e o ponto já foi também mencionado - as normas contidas nos Anexos só adquirem fôrça compulsiva em um Estado membro após incorporados à legislação desse mesmo Estado, por ato dela.

Evidentemente, a par dessa possibilidade, mantém-se a de que a infração seja punida pelo Estado em cujo território se verificou hinótese a que aludem as palavras iniciais do art. 12.

Em consequência, piloto de aeronave de matrícula brasileira, que, no Japão, infrinja regulamento de vôo ou manobra estabelecido por lei japonesa, poderá ser punido, indiferentemente, no Japão e segundo lei japonesa ou no Brasil e segundo lei brasileira.

A situação parecerá - e é - extraordinária. Mas não há dúvida de que o processo estabelecido mostra afinada sensibilidade a peculiares características da navegação aérea e procura sintonizar-se com elas.

Tem sido afirmado que a interpretação literal da última frase do art. 12 evitaria o entendimento sugerido, de vez que os Estados só se comprometem a assegurar a perseguição dos infratores e não a perseguí-los, isto é, só se comprometem a enseịar a punição e não a punir. Admitir procedência nessa afirmação seria não apenas esquecer a regra impositiva contida no período inicial do artigo ("Each contracting State undertakes to adopt measures to insure... that every aircraft carrying its nationality mark, wherever such aircraft may be, shall comply..."), mas também olvidar traços próprios da aviação.

Na hipótese atrás figurada, a dita interpretação literal conduziria à necessidade de forçar o piloto da aeronave brasileira a voltar ao Japão para ali ser punido - possívelmente com multa - além do que poderia envolver problemas de extradição - normalmente prevista apenas para crimes graves e não concedida em relação a nacionais. O procedimento, assim entendido, é complicado em demasia e só deixa como alternativa - por certo inconveniente - a impunidade. O meio têrmo que parece, ao mesmo tempo. justo e realista é o preconizado pela Convenção.

E, para reforçar o entendimento aduzido a partir dela, mencionemos possíveis argumentos concorrentes. 
Comparemos, por exemplo, o texto inglês autêntico e as versões francesa e espanhola, da Convenção. Estas últimas foram preparadas pela I.C.A.O., para propósitos internos da Organização; não obstante, seus têrmos são de alguma forma, indicativos. Assim, enquanto a redação inglesa diz: "Each contracting State undertakes to insure the prosecution...", na versão francesa lê-se: "Chaque Etat contractant s'engage à poursuivre...", e a espanhola estabelece: "Todo Estado contratante se compromete a proceder..." (27).

Lembramos, ainda, comunicação de MANKIEWICZ ao Sétimo Congresso Internacional de Direito Penal (Atenas, 1957) em que é discutido o texto da última frase do art. 12 da Convenção de Chicago. Essa comunicação inclui o trecho seguinte: "La rédaction curieuse de cette phrase dans le texto anglais s'explique probablement par le fait que certains Etats parties à la Convention de Chicago sont des Etats fédéraux dont la Constitution réserve aux Etats fédérés (provinces) l'exercice de la juridiction pénale, au moins en certaines matiéres. Dans ce cas, l'Etat fédéral, qu'il possède ou non le pouvoir législatif en matière pénale ou aeronautique, est dans l'impossibilité de poursuivre les delinquants, devant les tribunaux fédéraux et no peut done s'engager internationalement qu'à "assurer" sa porsuite devant les tribunaux des Etats fédérés (provinces). Cette interpretation peut s'appuyer sur l'argument supplémentaire tiré du fait que le premier projet de l'article 12 a été soumis à la Conference de Chicago par le Canada, qui est précisement um Ełat fédéral dont les tribunaux de première instance et d'appel relèvent des provinces" (28).

Assinalemos, finalmente, que a última sentença do art. 12 proveio diretamente do art. 25 da Convenção de Paris. E, com essa justificativa, recordemos que êste último preceito foi objeto de interpretação por parte da C.I.N.A., cujo pronunciamento se fêz nos têrmos seguintes: "Ces deux stipulations (I' article 25 de la Convention et le paragraphe 16 de l'Annexe H) visent l'application de penalités par um Etat pour des infractions commises hors de son territoire. L'article 25 prévoit la poursuite et la punition par um Etat, des infractions aux règlements prévious à l'Annexe $D$. commises par un aéronef partant la marque de notionaleté de cet Etat en quelque lieu q'il se trouvé... C'est aux Etats contractants qu'il appartient de prendre les mesuras législatives necessaires pour donner effet aux dispositions de l'article 25 de la Convention..." (29).

Sob o regime da Convenção de Chicago, pensamos impor-se conclusão em sentido semelhante: cada qual dos Estados-membros deve promulgar preceitos prevendo sanções para o caso de aeronaves de matrícula nacional infringirem regras relativas a vôo e manobra vigo-

(27) Ver I.C.A.O., Doc. 7300/2.

(28) Citado por Alex Meyer, "Les infractions commises à bord des aéronefs et leurs conse-

(29) Citado por Mankiewicz, o.c., pág. 118. 
rantes para além das respectivas fronteiras territoriais - em outros Estados, sôbre o alto mar ou em territórios não sujeitos a qualquer poder soberano.

\section{V}

Iniciativa em tal sentido não se tomou ainda pela totalidade dos Estados membros da Convenção de Chicago - parece-nos, em verdade, constituir uma exceção a já citada lei suíça. Importa, contudo, que as disposições do art. 12 da Convenção de Chicago sejam comple mentadas por competentes atos legislativos nacionais. Quando assim procederem os países que ainda não o fizeram, estará completado o processo de internacionalização do Direito Penal Aronáutico, na base assentada pela Convenção de Chicago, e ter-se-á atingido o ideal de não permitir que qualquer infração a regras do ar, onde quer que seja cometida, permaneça impune.

Miami, maio de 1962. 